\title{
As práticas-políticas curriculares em seus atravessamentos com as operações culturais cotidianas
}

\author{
Danielle Piontkovsky* \\ Carlos Eduardo Ferraço* \\ Maria Regina Lopes Gomes ${ }^{* * *}$
}

\section{Resumo}

O presente texto refere-se a pesquisas realizadas em escolas públicas de ensino fundamental e médio. Trata das tessituras dos currículos como criações anônimas produzidas nas operações culturais entre os praticantes cotidianos. Esses estudos problematizam os modos como são tecidos os currículos, considerando que essa tessitura diz respeito às ações culturais e políticas que se constituem nas redes de saberes-fazeres, e afirmam que as políticas curriculares expressam a potência dessas redes tecidas pelos praticantes para além do estabelecido nas propostas e/ou prescrições curriculares. Consideram os currículos como práticas-políticas e reconhecem a multiplicidade de conhecimentos tecidos nessas operações culturais como movimentos permanentes atravessados pelos movimentos inventados pelos sujeitos cotidianos. Assumem como perspectiva teórico-epistemológica as redes de conhecimento e como opção metodológica as práticas de pesquisa com os cotidianos, compreendendo narrativas, encontros e conversas como possibilidades para a produção dos dados. Os resultados dessas pesquisas indicam que as práticas-políticas de currículos pensadas a partir das articulações teóricas e dos diálogos entre os campos dos estudos culturais e pós-coloniais e das pesquisas com os cotidianos têm produzido o alargamento das experiências vividas entre os praticantes das escolas nos diferentes contextos culturais que habitam.

Palavras-chave: Cotidianos. Currículos. Operações culturais.

Recebido: 20/10/2015 - Aprovado: 15/02/2016

http://dx.doi.org/10.5335/rep.v23i1.6361

Doutora em Educação pela Universidade Federal do Espírito Santo. Professora de ensino básico, técnico e tecnológico no Instituto Federal do Espírito Santo. E-mail: danielle@ifes.edu.br

** Professor Associado da Universidade Federal do Espírito Santo e do Programa de Pós-Graduação em Educação desta instituição. E-mail: ferraco@uol.com.br

*** Professora do curso de Pedagogia do Departamento de Ensino da Universidade Vila Velha, ES. E-mail: regilogo@ hotmail.com 
Em nossas pesquisas, realizadas em escolas públicas de ensino fundamental e médio, ${ }^{1}$ temos problematizado os modos como são negociados os currículos realizados em meio às operações culturais que se constituem nos movimentos das redes cotidianas de saberes, fazeres, sentidos, afetos, valores, significados e poderes, entre tantas outras.

Assim, na tessitura deste artigo, entrelaçamos alguns aspectos que colocam em análise certas perspectivas teórico-epistemológicas que ainda apostam nos modos de identificação, padronização, homogeneização e monoculturação curricular, reduzindo o currículo a uma listagem de conteúdos e objetivos. Interessa-nos pensar o currículo em articulação permanente com os demais processos das políticas educacionais. Interessa-nos pensá-lo a partir dos efeitos dessas prescrições nas relações travadas nos cotidianos. Interessam-nos os diferentes usos (CERTEAU, 1994) que os professores fazem delas. Podemos dizer, usando os estudos de Certeau (1994), que esses praticantes vão inventando, fabricando, marcando com seus usos esses produtos que os docentes parecem aceitar passivamente, como consumidores de informações.

Por essa razão, defendemos a importância de pensar as redes e tessituras cotidianas dos currículos em sua complexidade (MORIN, 2007) e interdependência com os conhecimentos produzidos dentrofora ${ }^{2}$ das escolas, nos diferentes contextos de pertencimento dos praticantes cotidianos (CERTEAU, 1994), que também dizem respeito à fabricação e à negociação de políticas educacionais. Ou seja, modos que afirmam que as políticas curriculares expressam a potência dessas redes, para além do estabelecido nas propostas e/ou em qualquer tentativa de prescrição...

Segundo Alves, nesses processos, "[...] é indispensável compreender que no caso do cotidiano escolar, ao contrário do que foi dito em outras pesquisas, é impossível a existência de 'muros' entre as escolas e os 'contextos externos' ou a 'vida', por mais grades que sejam colocadas em torno das primeiras” (2005, p. 2).

Corroborando essas ideias, Carvalho nos indica que os currículos tecidos nos cotidianos envolvem as "[...] relações entre poder, cultura e escolarização, representando, mesmo que de forma nem sempre explícita, o jogo de interações e/ou relações presentes no cotidiano escolar" (2005, p. 96-97). Portanto, é importante o envolvimento nessas relações e nos diferentes contextos que configuram esses currículos, assim como as tentativas de apreender um pouco das redes que são tecidas nos múltiplos espaços-tempos cotidianos.

O importante é buscar compreender como os sujeitos das práticas tecem seus conhecimentos de todos os tipos, buscando discutir, assim, o que poderíamos chamar o fazer curricular cotidiano e as lógicas de tecer conhecimentos nas redes cotidianas, as das escolas, de seus professores/professoras e de seus alunos/alunas, dentre tantas (ALVES, 2002, p. 17, grifo da autora). 
Para tanto, em meio a essas múltiplas e variadas relações e usando as contribuições de Certeau (1995), trabalhamos com uma ideia de cultura como atos, como práticas que, para esse pesquisador, são sempre políticas. Portanto, falamos de práticas-políticas culturais que se tecem nos cotidianos de escolas e, como artes, proliferam-se nas relações, nos jeitos de falar, nas festas, nos usos dos uniformes, nos adereços, apelidos, nos modos de dar aulas, nos artefatos, nas emoções que afetam os corpos, entre tantas outras maneiras de tecer-viver-conhecer. Práticas-políticas que se apresentam como campos enredados e indissociáveis, proliferando-se e multiplicando-se na produção curricular e nos diferentes sentidos dos conhecimentos...

Damo-nos conta, assim, de que essas tentativas de padronização e de identificação curricular que pretendem controlar os cotidianos vividos são o tempo todo esgarçadas pelos movimentos táticos e astuciosos dos praticantes (CERTEAU, 1994) que habitam as escolas... Movimentos que provocam deslizamentos e se esparramam, minam essas estruturas, entram pelas fendas e produzem outras/novas fissuras na estrutura burocrática da educação e do currículo.

Dessa maneira, os praticantes, com seus relatos delinquentes, se deslocam e vivem, especificamente,

[...] nos interstícios dos códigos [...] com uma ordem firmemente estabelecida, mas suficientemente flexível para deixar proliferar essa mobilidade contestadora, desrespeitosa dos lugares, sucessivamente obediente e ameaçadora, que se estende das formas microbianas da narração cotidiana até as antigas manifestações carnavalescas (CERTEAU, 1994, p. 216-217).

Nesse sentido, a cultura passa, então, a ser concebida como uma construção social, como um lugar enunciativo (BHABHA, 1998), como aquilo que se constrói a partir das "marcas" colocadas pelos sujeitos em ambientes movediços, entrelugares culturais, em que esses sujeitos são autores de suas experiências, produtores de histórias... Propõe-se, portanto, que a cultura seja entendida como enunciação, constituindo-se em uma forma de produção irregular e incompleta de sentido e de valor, composta por demandas e práticas incomensuráveis, sempre produzida no ato da sobrevivência social.

[...] a cultura como enunciação se concentra na significação e na institucionalização [...]. O enunciativo é um processo mais dialógico que tenta rastrear deslocamentos e realinhamentos que são resultado de antagonismos e articulações culturais - subvertendo a razão do momento hegemônico e recolocando lugares híbridos, alternativos, de negociação cultural [...]. Cultura como lugar enunciativo, promulgador, abre a possibilidade de outros 'tempos' de significado cultural (retroativo, prefigurativo) e outros espaços narrativos (fantasmático, metafórico). Minha intenção ao especificar o presente enunciativo na articulação da cultura é estabelecer um processo pelo qual outros objetificados possam ser transformados em sujeitos de sua história e de sua experiência (BHABHA, 1998, p. 248). 
Sendo assim, com uma familiaridade em confronto com uma estranheza (CERTEAU, 1994), as redes de relações nas escolas se colocam para nós como cotidianos repletos de afetos e jeitos de viver-fazer que distanciam e aproximam relações, culturas, políticas e cumplicidades, nas quais estudantes e professores produzem suas vidas, resistem, silenciam, inventam, percorrem labirintos e constroem relações em múltiplas temporalidades e possibilidades de ampliação de seus conhecimentos. É preciso, então, assumir “[...] as escolas públicas como lugares (Certeau) onde, apesar de todas as pressões sofridas, a esperança é um dado de vida" (FERRAÇO, 2004, p. 79).

Redes que, diferente do que muitos dizem, subvertem prescrições e afirmam a potência desses encontros e da luta diária de muitos professores para alargar os limites dessas convivências, aproximando-se das várias realidades que pulsam no sonho e na ação de professores, alunos e da própria sociedade, que continua tentando inventar e reinventar a escola pública, apesar dos discursos de negação que pesam sobre essa instituição (LINHARES, 2000).

Desse modo, o interesse das pesquisas se amplia pelo fazer curricular cotidiano, ao considerar as hibridizações realizadas e as redes de relações vividas entre os sujeitos da pesquisa como possibilidades de ampliação de saberes-sentidos e de potências de vida; relações entre alunos e alunos, professores e alunos, professores e professores, e outros modos de interação presentes nos cotidianos. Dizemos isso por pensar nas questões anteriormente escritas e em tantas outras que surgem, não ampliando a busca por respostas, mas por novas tentativas de aproximação e implicação nas invenções curriculares dos praticantes nos cotidianos.

Afirmamos, assim, mais uma vez, que os processos cotidianos de tessituras das políticas educacionais, das políticas de formação continuada e de currículos que acontecem em meio às redes cotidianas não se reduzem às questões locais. Ao assumirmos os cotidianos vividos como espaços-tempos de produção dessas políticas, esses processos só podem ser compreendidos nos enredamentos, na complexidade das redes da educação.

$\mathrm{Na}$ busca por essas aproximações, usamos as conversas com professores e estudantes que, ao contarem o que fazem, vão trançando redes de conhecimentos (ALVES, 2008) sobre as escolas e suas vidas, isto é, criando currículos em meio às ações culturais e políticas vividas. Ferraço afirma que, ao contrário do que ainda vivenciamos nas relações cotidianas,

[...] qualquer tentativa de análise, discussão, pesquisa ou estudo com o cotidiano só se legitima, só se sustenta como possibilidade de algo pertinente, algo que tem sentido para a vida cotidiana, se acontecer com as pessoas que praticam esse cotidiano e, sobretudo, a partir de questões e/ou temas que se colocam como pertinentes às redes cotidianas (2007, p. 78 , grifo nosso). 
Nesses espaços-tempos de fronteiras, deslocamentos, discursos e traduções culturais, forjam-se os currículos hibridizados, nos quais professores e alunos, de modo especial, lidam com a diferença, ao buscar negociá-la. Trata-se de um fazer curricular entendido como produção de sentidos, sempre híbridos e negociáveis, em que o discurso da diferença não aparece atrelado às hierarquias e aos binarismos fixos de uma dada referência cultural, mas constituído a partir da afirmação da heterogeneidade.

[...] o currículo passa a ser, assim, um lugar-tempo em que [...] as culturas presentes precisam co-existir, em que as diferenças precisam ser traduzidas. Uma tradução sempre impossível, mas que transforma todas as culturas particulares ao obrigá-las a negociar no horizonte mais amplo das experiências homogeneizantes (MACEDO, 2004, p. 26-27).

Nesse sentido, fortalecendo o protagonismo dos praticantes nas pesquisas com os cotidianos, conforme Certeau (1994), vamos compreendendo, a partir do que esses praticantes têm a nos dizer, que se abrem outros possíveis de pensar a vida, a educação e a escola, para além dos modelos estratégicos da ciência moderna de valorização de certos saberes e práticas articulados como produção de verdades. Para esse autor, as conversas com os sujeitos ordinários:

[...] são práticas transformadoras de "situações de palavras", de produções verbais onde o entrelaçamento das posições locutoras instaura um tecido oral sem proprietários individuais, as criações de uma comunicação que não pertence a ninguém. A conversa é um efeito provisório e coletivo de competências na arte de manipular "lugares comuns" e jogar com o inevitável dos acontecimentos para torná-los "habitáveis" (CERTEAU, 1994, p. 50).

Acreditando nessas conversas, buscamos viver experiências (LARROSA, 2004) e nos aproximamos desses professores e alunos tentando captar essas sutilezas e movimentos, sentidos nos corpos que habitam essas vozes e que, de diferentes modos, gritam, tagarelam, sussurram e suspiram os efeitos de realidade dessas políticas educacionais.

Nossa aposta está na escuta dessas vozes singulares que tornam vivas e tecem as teorias das práticas (CERTEAU, 1994), que consistem em um fluir de interações articuladas aos intercâmbios desses praticantes cotidianos, trazendo-as para o texto como referências para as problematizações dessas políticas e diferentes culturas. Vozes e narrativas que, para fazerem sentido, segundo Certeau (1994), precisam ser contadas de novo, ouvidas outra vez...

Ferraço (2003) também nos encaminha nessa direção quando afirma que ao invés de pesquisar sobre, dediquemo-nos, então, a pesquisar com, e essa opção nos move a trabalhar com as narrativas dos sujeitos das escolas como pistas para entendimento da produção de políticas de currículo em suas relações com processos de formação. 
Alves (2005), por sua vez, considera necessário discutir algumas críticas feitas ao uso de narrativas em trabalhos de pesquisadores preocupados com o cotidiano. Uma dessas críticas refere-se à multiplicidade de sentidos que essas situações evocam:

Nessas pesquisas, ouvir uma narrativa [...] traz, a cada um que ouve, dentro das redes de conhecimentos e significados a que pertence, a possibilidade de "ver", "sentir", "entender", e "ouvir" coisas muito diferentes. A questão é saber se isto significa, apenas, as dificuldades de uso desses recursos ou indica a ampliação de possibilidades na análise de uma dada situação, exigindo que incorporemos, necessariamente, a complexidade e a potencialidade que cada acontecimento traz em si. Os que trabalham com as pesquisas nos/dos/com os cotidianos tendem a adotar essa segunda posição (ALVES, 2005, p. 8).

De fato, entre as práticas enunciativas dos contextos das políticas oficiais e as práticas enunciativas dos contextos dos cotidianos, abre-se "[...] a possibilidade de analisar o imenso campo de uma 'arte de dizer' [e de fazer] diferente dos modelos que reinam de cima para baixo" (CERTEAU, 1994, p. 86), ou seja, essas artes de contar dos praticantes cotidianos, que narram lances, golpes, não verdades, vão desvelando modos de viver, conhecer e sentir que estão em jogo nessas relações, marcando, por seus usos, esses discursos (CERTEAU, 1994). E aqui fica nosso convite para que todos ouçam essas músicas de sons e de sentidos e entrem na dança, se desejarem compreendê-las.

Assim, em conversas com professores, sobre os processos de produção curricular e formação, ficamos sabendo:

A escola se tornou lugar de tudo. Tudo chega à escola e nós, professores, estamos perdendo nossa função de ensinar, de trabalhar com os conhecimentos... Somos pais, mães, assistente social, tudo! (ISADORA, professora).

Acho que eles estão trazendo as aprendizagens da rua para a escola e está ficando cada vez mais difícil... (OLAVO, professor).

Eles não se interessam pelas aulas que eu dou. Sou professor de Geografia. Só quando invento alguma coisa no laboratório ou algum filme, eles se interessam, mas não dá para ficar inventando o tempo todo. Eles acham chato ficar na sala lendo, copiando, mas, quando uso mapas, eles gostam. Até eu acho chato... Eu acho que a escola é um lugar de interação, de aprendizagens e de produzir conhecimentos. Eu sou sociointeracionista... Mas o que acontece aqui, na escola, não é isso... (ANDRÉ, professor).

Apesar das misturas presentes nessas falas, parece-nos ainda predominante uma maneira de pensar que aponta o caráter monocultural da escola e, por sua vez, do currículo. Podem ser "pistas" (GINZBURG, 1989) provocadoras da necessidade de produção de outros modos de constituição das relações nas escolas, que apontem práticas curriculares e formativas em que a questão da diferença se faça cada vez mais presente. Do mesmo modo, convocam-nos nessas problematizações a compre- 
ender os espaços-tempos (ALVES, 2001) escolares como cruzamentos culturais, fluidos e complexos, atravessados por tensões e conflitos (MOREIRA; CANDAU, 2006). Nas conversas com alguns alunos, parece que essas redes se ampliam quando eles fazem seus relatos:

Tem muita coisa que acontece também porque os próprios alunos inventam, assim, mas com a ajuda das coordenações e o trabalho do Grêmio! São as atividades que a gente chama de culturais, mas que aprendemos muito também, como: sarau, exposição, teatro, aula de dança, show de talentos, várias coisas... e começa lá na Semana de Acolhida, logo que o primeiro ano chega... Alguém já falou sobre isso?!?! Eu quero falar... é que a gente já começa aprendendo a se relacionar melhor com as pessoas, a respeitar, a colher o que planta logo que chega, literalmente, porque a gente faz o plantio de árvores! [Risos...] É o que se chama aqui de trote solidário... (KUKI, aluno).

Olha, aqui, na escola, acontece muita coisa legal... Quem se interessa aprende muita coisa mesmo! As aulas de campo, as visitas técnicas, as atividades na biblioteca, nos laboratórios... Sabe, a gente tem muito recurso! Não falta nada para o aluno que quer aprender: computadores, internet, livros de todas as matérias, bons professores, mas tem que se dedicar, né? Também tem coisa ruim, como algumas aulas, mas a gente também tem que aguentar um pouco, né? Ah... tem outra coisa que esqueci de falar: como tem muito professor da área técnica, acontecem projetos de várias áreas de atuação deles... Têm bolsas, estágios, monitorias, ou seja, oportunidades pra aprender e ainda ganhar um dinheirinho... (MARIOLA, aluna).

É... aqui aprendemos mesmo muita coisa!... Coisa boa e coisa ruim... Foi difícil demais no começo e tá sendo bem difícil agora no final também... Os segredos, as colas, as conversas, as tarefas, as festas... dividimos tudo aqui... até a morte! (ESPANHOLA, aluna).

Em nossas andanças pelas escolas públicas, entramos nessas conversas que nos levaram a pensar os espaços-tempos das escolas e as práticas-políticas de currículo que aí se tecem em seus atravessamentos sociopolíticos e culturais, sempre presentes nessa relação com os conhecimentos escolares. Atravessamentos que deslocam e transformam as estratégias de controle e regulação das práticas curriculares, tecendo uma multiplicidade de redes entre esses praticantes que afetam as relações, inventando outros sentidos para os currículos, os conhecimentos, as escolas e as políticas educacionais.

Ferraço (2005), quando faz referência à complexidade da educação e às redes cotidianas, contribui significativamente com essas reflexões, pois considera, em suas análises, os diversos atravessamentos que falam, na maioria das vezes, dos conturbados movimentos e enfrentamentos vividos nas instituições educacionais... “[...] queiramos ou não, as redes cotidianas estão atravessadas por diferentes contextos de vida e valores, o que, a nosso ver, proporciona a dimensão de complexidade para a educação que defendemos, ou seja, complexo por ser tecido junto no cotidiano vivido" (2005, p. 31).

Assim, aos fios de conversas com professores e estudantes alinhamos as contribuições de Bhabha (2011), como tentativa de compreender esses variados e, muitas 
vezes, invisibilizados atravessamentos de uma vida que parece "invadir" as escolas e salas de aula, fazendo sempre outras as práticas docentes. Quando nos chama a atenção para questões culturais, esse autor nos lembra de que:

[...] se olharmos para a relação das culturas [...] as veremos como parte de um processo complexo de modernidade "minoritária", e não simplesmente de uma polaridade de uma maioria e minoria, o centro e a periferia [...]. De um espírito de resistência, surge a vontade minoritária de viver, de fazer, de introduzir o ato de poiesis na vida imaginada do imigrante ou da maioria como parte da sociedade cívica civil (BHABHA, 2011, p. 185, grifo nosso).

De acordo com Certeau (1995), são as milhares de redes informais que circulam em múltiplos contextos e os fluxos de informações que garantem intercâmbios que fazem com que uma sociedade não se asfixie e morra. Mais do que um conjunto de "valores" que devem ser defendidos ou ideias que devem ser promovidas, a cultura tem hoje a conotação de um trabalho que deve ser realizado em toda a extensão da vida social.

[...] a cultura "não consiste em receber, mas em realizar o ato pelo qual cada pessoa marca aquilo que lhe dão para viver e pensar [...]". Toda cultura requer uma atividade, um modo de apropriação, uma adoção e uma transformação pessoais, um intercâmbio instaurado em um grupo social (CERTEAU, 1995, p.168).

Partindo desses apontamentos, as imagens de escolas, trazidas nas conversas por Isadora, Espanhola, Olavo e outros, podem então nos dizer que se torna cada vez mais urgente reconhecer essas práticas como políticas dos cotidianos que se constituem a partir de movimentos, de processos de articulação e negociação entre os diferentes praticantes que tramam os cotidianos das escolas. Políticas que, nas dinâmicas das relações, são tecidas silenciosamente como uma água a escorrer e dão pistas de um desejo comum "de criar uma pólis e uma política; onde exista vontade de organizar as condições de vida em função de motivos para viver" (CERTEAU, 1995, p. 34).

Os entrelaçamentos desses fios das conversas, portanto, nos colocam diante de alguns enfrentamentos e tensões dos cotidianos, provocando nosso pensamento em relação a outros modos de compreender os processos de constituição das políticas educacionais, especialmente aquelas que tecem os currículos e os processos de formação docente. São inúmeros os imprevistos, são incontroláveis as transformações, são efêmeros os movimentos...

Assim, na tentativa de acompanhar essas redes, buscando compreender os efeitos desses fios de realidade que se tramam nos cotidianos das escolas entre professores, estudantes e demais praticantes das práticas-políticas de currículo, em seus entrelaçamentos com as culturas, continuamos ouvindo esses sujeitos... 
Às vezes acontecem umas coisas que eu acho que é só aqui mesmo... Enrolar uns professores é fácil demais. Na verdade, não é nem a gente que enrola, eles é que não estão preocupados se a gente aprende! [...] Vê bem, um professor de animais, do técnico, por exemplo, passava os trabalhos pra gente, as tarefas... aí a gente começou a desconfiar que ele só dava o visto, mas nem lia. O que eu fiz? Num dos deveres respondi coisas de outra matéria, nada a ver... [...] Sabe o que aconteceu? Nada! Voltou com o visto como se tivesse tudo certo, ou seja, não leu... [...] De que adianta uma tarefa dessas? Se a gente erra ou acerta, tá tudo bem... (KUKI, aluno).

O transitar nessas redes, conversando com esses praticantes cotidianos, nos impregnou de diferentes sentidos de escolas que eles produzem... As aulas se tornam "chatas", mas parecem concordar que as escolas são espaços-tempos de interação e de aprendizagens... As redes de amizade e afeto são tecidas o tempo todo, para além dos conteúdos previstos nas disciplinas... A escola se torna um lugar de trançar fios de amizade, que só são rompidos com a morte... Escola para feitura das festas! Salas de aula, pátios, dormitórios, entre outros tantos espaços-tempos de encontros, vão produzindo, entre esses sujeitos ordinários, sentimentos de pertencimentos e afastamentos...

Diante desses movimentos, Linhares (2010) nos lembra dos riscos das generalizações presentes nos discursos oficiais de educação, produzidos de fora das escolas, afastados das experiências docentes que parecem apostar em uma maneira idealizada de ensinar, em um modelo formal de organização da escola, em um modo de aprender, de avaliar, de organização curricular, de ser professor, de ser aluno, entre tantos outros modelos.

Tecendo e ampliando essas conversas com outros fios trazidos por Linhares (1999), podemos inferir que discursos que naturalizam a negação da escola pública parecem desconhecê-la como espaço-tempos de resistências, de lutas e de invenção de formas múltiplas de sobrevivência, de alternativas escolares/pedagógicas/ políticas, frutos de diferentes práticas dos sujeitos históricos, sociais, culturais e políticos que não renunciam à dignidade da emancipação humana (LINHARES, 2000). E, ainda, que o discurso da negação da escola pública e do esquecimento dos professores procede a um verdadeiro "assassinato cultural", à medida que silencia e emudece os sujeitos que acabam por ocupar lugares subalternizados, "definidos por processos globalizadores, que vão sendo operados à nossa revelia" (LINHARES, 1999, p. 80).

Entendo que a ajuda que a Política Educacional poderia trazer está muito longe deste exercício etnocêntrico de refundar o mesmo, pois sua maior potência reside em desestabilizar velhas formas de poder, para provocar-nos a imaginar mundos novos capazes de responder às nossas esperanças, que precisam ser reacendidas (LINHARES, 2000, p. 85). 
Na contramão desses discursos, em nossas pesquisas com os cotidianos (FERRAÇO, 2003), apostamos nas políticas de currículo, em seus enredamentos com as práticas culturais, apesar das cegueiras ainda encontradas nas escolas diante da pluralidade e da diferença, muitas vezes, silenciadas pela insistência nas práticas de homogeneização e padronização. Desse modo, segundo Moreira e Candau, "[...] abrir espaços para a diversidade, a diferença e para o cruzamento de culturas constitui o grande desafio que [a escola] está chamada a enfrentar" (2006, p. 41).

Sendo assim, não pretendemos retomar a discussão sobre o que é, como se tivéssemos uma verdade a dizer sobre os currículos. Nossas pesquisas buscam, a partir das teorias das práticas (CERTEAU, 1994) que se tecem e se produzem nos cotidianos, compreender os diferentes modos de constituição dos currículos em meio às ações culturais, afirmando uma noção de currículo que faz transbordar os textos oficiais, já que as escolas se constituem como espaços-tempos de relações múltiplas entre múltiplos sujeitos com saberes múltiplos, que aprendem-ensinam, o tempo todo, múltiplos conteúdos de múltiplas maneiras, nos múltiplos cotidianos vividos (ALVES, 2001).

Reconhecendo a potência da vida que pulsa nas escolas como uma ação criadora, assumimos, em nossas pesquisas, uma atitude ético-política de buscar compreender o conhecimento tecido em cada ação cotidiana (ALVES, 2003) "com" os praticantes das escolas. Fazemos, então, uma tentativa de ratificar a potência dos diferentes sentidos enunciados pelos protagonistas dos cotidianos, não por boa vontade ou gratidão (FERRAÇO, 2003), mas pela crença nos processos que falam das vivências, das multiplicidades, das singularidades das relações cotidianas e dos possíveis de criarmos e recriarmos a nós mesmos e o mundo (MATURANA, 2001).

Assim, as pesquisas não têm a intenção de analisar o cotidiano a partir do paradigma das certezas e das verdades absolutas, ou seja, "[...] de tentar propor à realidade o que ela deveria ser" (OLIVEIRA, 2007, p. 114), mas pretendem contribuir para trazer à cena a potência das relações e emoções, dos encontros e confrontos que acontecem nos espaços-tempos das escolas, em suas articulações com outros contextos, que nos ajudam a pensar e a compreender as invenções desses sujeitos ordinários (CERTEAU, 1994), em redes que se constituem e hibridizam as práticas escolares...

Procuramos evidenciar algumas marcas deixadas nas produções dos currículos, assim como as práticas inventivas que vão produzindo outros sentidos para o conhecimento, pois, para as nossas pesquisas, interessa ouvir o que os praticantes cotidianos das escolas têm a nos dizer, o que fazem, o que pensam, o que sentem... Interessa-nos como fazem as aulas e tecem as redes que movem as escolas, pois compreendemos, como Alves, que essas são produções de histórias públicas que 
atualizam as histórias das escolas e dos currículos, uma vez que "[...] interessa mais o que dizem do que aquilo que gostaríamos de ouvir" (2008, p. 139).

Nesse sentido, assumindo o processo de hibridação que acontece nas relações, nas discussões ligadas às teorias-práticas cotidianas e associando a educação e o currículo aos processos culturais mais amplos, não há como negar a "importância dos fluxos de significados que se estabelecem entre diferentes campos e sujeitos" (LOPES; MACEDO, 2002, p. 49). Portanto, é possível afirmar que, nesses espaços-tempos de fronteiras, deslocamentos, discursos e traduções culturais, em que professores e alunos, de modo especial, lidam com a diferença, ao buscar negociá-la, forjam-se os currículos hibridizados.

\section{Practice-policies curriculum in its crossings with cultural daily operations}

\section{Abstract}

This text refers to surveys conducted of public elementary and secondary education. Deals with the tessitura of curricula as anonymous creations produced in cultural operations between daily practitioners. These studies problematize the ways in which curricula are woven considering this fabric relates to cultural and political actions that are in the know-doings networks. They claim that the curricular policies express the power of these networks woven by practitioners in addition to the set of proposals and / or curricular prescriptions. Consider the curricula as political practices and recognize the multiplicity of tissues knowledge in cultural operations as permanent movements crossed by the arts invented by daily subjects. Assume as theoretical and epistemological perspective the knowledge networks and as a methodological option the practices of research with the daily, perceiving narratives, meetings and conversations as possibilities for compiling the data. The results of these reaches indicate that the practices-political of the curricula designed from the theoretical links and dialogue between the fields of Cultural Studies and Post-Colonial and Research with the daily have produced the extension of experiences among practitioners of schools in different cultural contexts they inhabit.

Keywords: Cultural operations. Curricula. Daily.

\section{Notas}

1 As escolas de ensino fundamental e médio estão localizadas nas cidades de Vitória e Santa Teresa, no estado do Espírito Santo.

2 A junção das palavras, fazendo-as novas expressões, se dá, como bem explica Alves, por um “[...] esforço presente nas pesquisas com os cotidianos de superar as heranças da Modernidade, entre as quais, o pensamento em dicotomias, que foi tão necessário à lógica das ciências” (2010, p. 55). 


\section{Referências}

ALVES, N. Artefatos tecnológicos relacionados à imagem e ao som na expressão da cultura de afro-brasileiros e seu "uso" em processos curriculares de formação de professoras na Educação Superior. Projeto incorporado ao Prociência, agosto de 2005. Mimeo.

Decifrando o pergaminho: o cotidiano das escolas nas lógicas das redes cotidianas. In: OLIVEIRA, I. B. de; ALVES, N. (Org.). Pesquisa no/do cotidiano das escolas: sobre redes de saberes. Rio de Janeiro: DP\&A, 2001. p. 13-38.

. No cotidiano da escola se escreve uma história diferente da que conhecemos até agora. In: COSTA, M. V. (Org.). A escola tem futuro. Rio de Janeiro: DP\&A, 2003. p. 81-102.

. Nós somos o que contamos: a narrativa de si como prática de formação. In: SOUZA, E. C. de; MIGNOT, A. C. V. Histórias de vida e formação de professores. Rio de Janeiro: FAPERJ, 2008. p. 37-52.

. Redes educativas "dentrofora" das escolas exemplificadas pela formação de professores. In: DALBEN, Â. et al. (Org.). Convergências e tensões no campo da formação e do trabalho docente. Belo Horizonte: Autêntica, 2010. p. 49-66.

BHABHA, H. K. O bazar global e o clube dos cavalheiros ingleses: textos seletos. Rio de Janeiro: Rocco, 2011. Organização de Eduardo F. Coutinho.

. O local da cultura. Tradução de Myriam Ávila, Eliana Lourenço de L. Reis e Gláucia R. Gonçalves. Belo Horizonte: Editora UFMG, 1998.

CARVALHO, J. M. Pensando o currículo escolar a partir do outro que está em mim. In: FERRAÇO, C. E. (Org.). Cotidiano escolar, formação de professores(as) e currículo. São Paulo: Cortez, 2005. p. 94-111.

CERTEAU, M. de. A cultura no plural. Campinas: Papirus, 1995.

A invenção do cotidiano 1: artes de fazer. Rio de Janeiro: Vozes, 1994.

FERRAÇO, C. E. Currículo, formação continuada de professores e cotidiano escolar: fragmentos de complexidade das redes vividas. In: FERRAÇO, C. E. (Org.). Cotidiano escolar, formação de professores (as) e currículo. São Paulo: Cortez, 2005. p. 15-42.

. Currículos e conhecimentos em redes: as artes de dizer e escrever sobre a arte de fazer. In: ALVES, Nilda; GARCIA, Regina Leite (Org.). O sentido da escola. 4. ed. Rio de Janeiro: DP\&A, 2004. p. 121-150. abr. 2007.

. Pesquisa com o cotidiano. Educação e Sociedade, Campinas, v. 28, n. 98, p. 73-95, jan./

. Eu, caçador de mim. In: GARCIA, R. L. Método: pesquisa com o cotidiano. Rio de Janeiro: DP\&A, 2003. p. 157-175.

GINZBURG, Carlo. Mitos, emblemas e sinais: morfologia e história. São Paulo: Companhia das Letras, 1989.

LARROSA, J. Linguagem e educação depois de babel. Belo Horizonte: Autêntica, 2004. 
LINHARES, C. F. Escola Balaia: um convite ao debate para reinvenção de Caxias. Caxias, MA: Caburé, 1999.

A importância de se abrir espaço para memórias e narrações. 2000. Entrevista concedida ao Portal Multirio sobre a relação entre a questão da identidade no mundo de hoje e a "crise da escola". Disponível em: <http://www.multirio.rj.gov.br>. Acesso em: 12 ago. 2008.

Formação de professores: definir ou interrogar tendências? In: GARCIA, R. L. (Org.). Diálogos cotidianos. Petrópolis: DP et Alii; FAPERJ, 2010. p. 157-168.

LOPES, A. C.; MACEDO, E. (Org.). Currículo: debates contemporâneos. São Paulo: Cortez, 2002.

MACEDO, Elizabeth. Currículo e hibridismo: para politizar o currículo como cultura. Educação em Foco, Juiz de Fora: Editora UFJF, v. 8, n. 1-2, p. 13-30, 2004.

MATURANA, R. H. Cognição, ciência e vida cotidiana. Belo Horizonte: Editora UFMG, 2001.

MOREIRA, A. F.; CANDAU, V. M. O/a educador/a como agente cultural. In: LOPES, Alice Casimiro; MACEDO, E. F. de.; ALVES, M. P. C. (Org.). Cultura e política de currículo. Araraquara: Junqueira \& Marin, 2006. p. 110-126.

MORIN, E. Introdução ao pensamento complexo. Porto Alegre: Sulina, 2007.

OLIVEIRA, I. B. O campo de estudos do cotidiano e sua contribuição para a pesquisa em educação. In: SCHWARTZ, M. C. et al. (Org.). Desafios da educação básica para pesquisa em educação. Vitória: Edufes, 2007. p. 107-127. 